\title{
Past global changes as indicators for future changes and strategies for sustainability
}

\section{futurearth}

Research. Innovation. Sustainability.

\author{
Marie-France Loutre', P.A. Gell2, K.J. Meissner ${ }^{3}$ and B. Vannière ${ }^{4}$
}

Online, 15 June 2021

PAGES organized a session during the hybrid Sustainability Research \& Innovation Congress 2021 (SRI2021; pastglobalchanges. org/calendar/26956), a joint initiative of Future Earth and the Belmont Forum, which was led by the Commonwealth Scientific and Industrial Research Organisation (CSIRO) and Future Earth Australia.

International reports on climate, biodiversity and ecosystems, such as the Intergovernmental Panel on Climate Change (IPCC) and Intergovernmental Platform on Biodiversity and Ecosystem Services (IPBES), describe the unprecedented changes that the Earth system has experienced over the last few decades. While the data are clear, it is difficult for a human being to identify these changes and their potential consequences-partly because our individual memory is short, and partly because on a daily or annual basis we experience much larger changes and quickly adapt and get used to new conditions. In other words, we struggle to identify the baselines of changes and how these baselines shift with time. Therefore, it is important to identify reference points for the most recent changes, or at least to be aware of how humans are shaping the climate and ecosystems.

Human-induced climate change is altering some of the processes that underlie modes of climate variability that can have major impacts on societies. Short observational records make it difficult to understand the full range of natural climate variability and to robustly detect recent changes in these modes of variability. Nerilie Abram reviewed paleoclimate evidence for changes in the El Niño-Southern Oscillation, Indian Ocean Dipole and Southern Annular Mode during the last millennium. She discussed how unusual some of these phenomena have been over recent years and gave perspectives on the likely future of these systems (Fig. 1a).

Michael Reid described the deep history of human impacts on aquatic ecosystems. He highlighted how paleoecological reconstructions can provide avenues to determine impacts on ecosystems caused by human activities, including activities that took place long before the establishment of systematic ecological monitoring. He stressed the importance of understanding the relative and interactive effects of multiple stressors and showed, with an interesting example from the Murray-Darling Basin in Australia, the need to address all stressors, not just the most recent ones (Fig. 1b).
Threats to property and people linked to floods are becoming more and more important, in particular because of increasing population densities in areas prone to flooding. Furthermore, the magnitude, frequency, and timing are changing, thus exacerbating the issue. Extreme flooding can be documented through historical, botanical, and geological records. Bruno Wilhelm reviewed how these archives record floods and the information they can provide (Fig. 1c). He then showed how the flood risk assessment can be improved with these records and discussed avenues for improvement. Flood management and mitigation plans should take this information into account.

Simon G. Haberle provided a long-term perspective on the 2019-2020 Australian Bushfire Crisis. The paleoecological records from pollen and charcoal show an increase in fire activity during times of past climate change - particularly during transitions from cooler to warmer climates. The presence of humans on the Australian landscape for at least the last 65,000 years appears to have mediated past climate impacts on fire regimes and fire sensitive ecosystems through Aboriginal fire management practices. The cessation of these landscape management practices across much of Australia with the start of European colonization more than
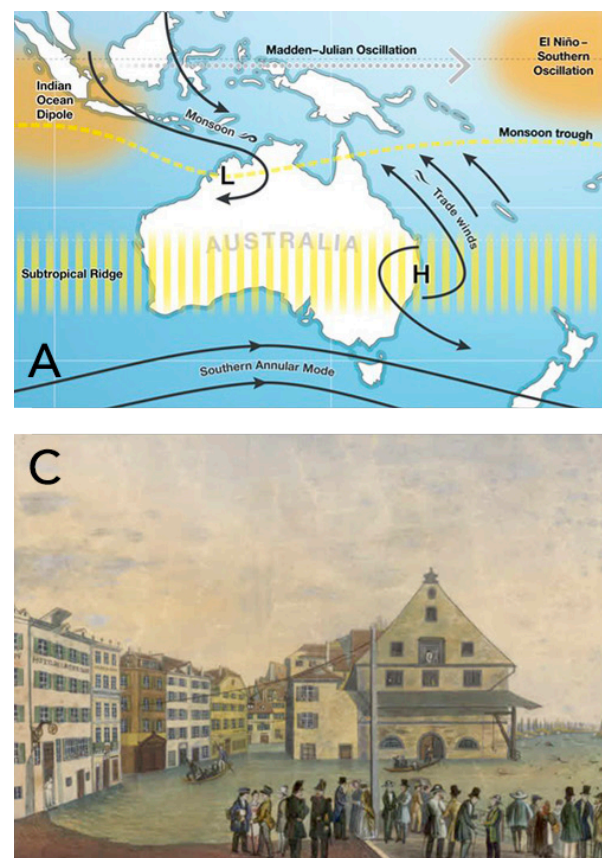

Figure 1: Illustration of the four topics discussed during this session. (A) Modes of climate variability; (B) human impacts on aquatic ecosystems; (C) flood and (D) fire hazards.

Image credits: (A) Australian Government, Bureau of Meteorology; (B) Peter Gell; (C) Meteoschweiz (Gasthaus zur Krone, Basel; Staatsarchiv Basel-Stadt, BILD13, 323); (D) Matthew Abbot (Lake Conjola, 31 Dec 2019; matthewabbott.com.au/PHOTOJOURNALISM/Black-Summer/1).
200 years ago induce a shift from low but persistent levels of burning to a much more variable fire regime pattern (Fig. 1d).

The session concluded with a fruitful panel discussion. The importance of past climate and ecosystem reconstructions was discussed, especially in light of their capacity to improve risk assessments related to current and future changes. The need to improve communication channels between past global change experts and policy makers or other end users, such as insurance companies, was also highlighted. Overall, this session successfully brought together experts from different areas of the climate system and ecosystems to discuss changes, transitions, and resilience of vital systems upon which our well-being depends.

\section{AFFILIATIONS}

Past Global Changes International Project Office,

Bern, Switzerland

${ }^{2}$ Faculty of Science \& Technology, Federation University Australia, Ballarat, Australia

${ }^{3}$ Climate Change Research Centre, University of New South Wales, Sydney, Australia

${ }^{4}$ Chrono-environnement, CNRS - Université de

Franche-Comté, Besançon, France

\section{CONTACT}

Marie-France Loutre: marie-france.loutre@pages.unibe.ch
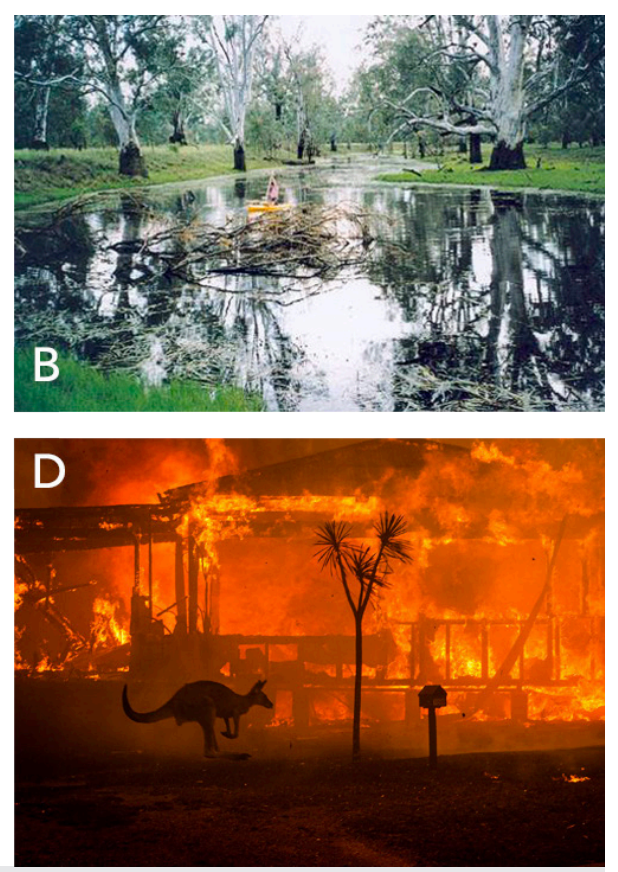